\title{
Sex and race differences in young people's responsiveness to price and tobacco control policies
}

\author{
Frank J Chaloupka, Rosalie Liccardo Pacula
}

Economics

Department,

University of Illinois at

Chicago, Chicago,

Illinois, USA

F J Chaloupka

RAND Corporation, Santa Monica, California, USA

Rosalie Liccardo Pacula

Correspondence to: Dr FJ Chaloupka,

Economics Department

$(\mathrm{M} / \mathrm{C} 144)$, University of

Illinois at Chicago, $601 \mathrm{~S}$

Morgan Street, Chicago,

Illinois 60607, USA

email: fjc@uic.edu

Received 1 May 1999 Accepted 26 June 1999

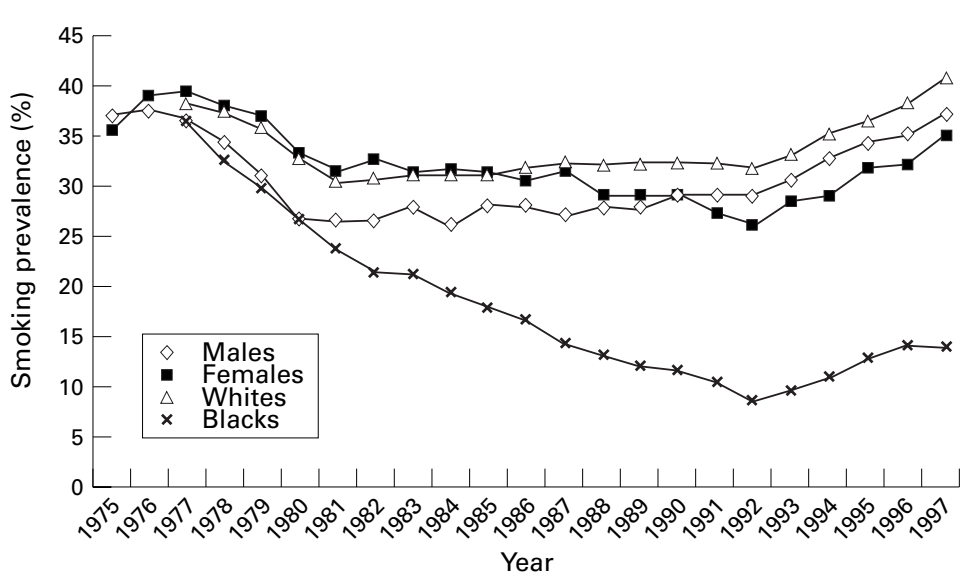

Figure 1 Thirty-day smoking prevalence among high-school seniors. Historical data from the Monitoring the Future surveys 1975-97. surveys.

Main outcome measure-Thirty-day smoking prevalence.

Results-Young men are much more responsive to changes in the price of cigarettes than young women. The prevalence elasticity for young men is almost twice as large as that for young women. Smoking rates of young black men are significantly more responsive to changes in price than young white men. Significant differences in responsiveness to particular tobacco control policies also exist. These differences, however, explain relatively little of the differences in smoking prevalence among young population subgroups.

\begin{abstract}
Objective-To determine if there are differences in young people's responsiveness to price and tobacco control policies for population subgroups and to examine whether or not these differences, if they exist, can explain sex and racial differences in trends in the prevalence of smoking in young people in the United States.
\end{abstract}

Design-Use cross-sectional and intertemporal variation in local and state tobacco control policies and prices to calculate demand responses to these policies using regression analysis techniques.

Subjects-A nationally representative sample of American eighth grade (ages 13-14 years), 10th grade (15-16 years) and 12th grade (17-18 years) students obtained from the 1992-1994 Monitoring the Future 1980 s, but the declines are not nearly as large as those observed among young blacks. Smoking rates in young men and young whites, however, levelled off in the early 1980s and started to climb slowly throughout the 1980s. Interestingly, from 1991 to 1996 there is again a parallel movement in the smoking rates of these four groups, but now smoking rates among young men are higher than smoking rates among young women.

What caused these dramatic differences in smoking rates during the 1980 s? One possible explanation is that there was a large change in a significant predictor of young people's smoking during this time period that influenced these four groups differently. For example, between 1981 to 1990 , the average real price of a pack of 20 cigarettes rose from a 25 -year low 
of US $\$ 0.69$ to $\$ 1.10 .^{2}$ This represents a $63 \%$ increase in the real price of a pack of cigarettes. Previous economic research shows that young people are sensitive to changes in the price of cigarettes. ${ }^{3}$ It may be that this significant price increase influenced smoking rates of young population subgroups differently.

In this paper we examine differences in young people's responsiveness to changes in price and specific tobacco control policies using a nationally representative sample of young people from the Monitoring the Future surveys. We find that significant differences do exist, by sex and by race. For example, young men are much more responsive to changes in the price of cigarettes than young women; the prevalence elasticity for young men is almost twice as large as that for young women. Further, we find that smoking rates of young black men are significantly more responsive to changes in price than those for young white men. We also find that there are significant differences in young people's responsiveness to tobacco control initiatives by race. Smoking rates among young whites are much more responsive than among young blacks to anti-tobacco activities and clean indoor air restrictions. Smoking rates among young blacks, on the other hand, are significantly influenced by smoker protection laws and restrictions on youth access, whereas smoking rates among young whites are not.

\section{Methods}

Data on young people's smoking prevalence come from the 1992-1994 Monitoring the Future surveys of eighth grade (ages 13-14 years), 10th grade (15-16 years) and 12 th grade (17-18 years) students living in the contiguous United States conducted by the Institute for Social Research (ISR) at the University of Michigan. Every year since 1975, the ISR has collected data on tobacco, alcohol, and other drug use from a nationally representative sample of approximately 17000 high-school seniors. In 1991, comparable surveys of eighth and 10 th grade students were added. The survey is conducted in school and addresses young people's attitudes, perceptions, and use of legal and illicit drugs. Given the sensitive nature of the subject matter, great care is taken to ensure reliable and valid responses. For example, parents are not informed of their child's responses.

From responses to these surveys, a dichotomous indicator of smoking prevalence is constructed that is set equal to one for young people reporting any cigarette consumption in the previous 30 days and zero otherwise. In addition, various other socioeconomic and demographic variables can be constructed from the general background data that are collected. Variables used in this analysis include: sex (male or female), race (white, black, and other race), age, average weekly income from all sources (employment, allowances, and other), current grade (eighth, 10th, or 12th), marital status (married/engaged or single), parental education (less than high-school graduate, high-school graduate, more than high-school graduate), family structure (live alone, only mother present, only father present, both parents present, live with other(s)), mother's work status while the child was growing up (not employed, employed part-time, employed fulltime), existence of siblings, average number of hours worked weekly, living in rural/urban area, and frequency of participation in religious services (no participation, infrequent participation, and frequent participation). Year dummy variables are also included for 1992 and 1993 to control for differences in smoking rates across time.

Based on each person's county of residence, measures of cigarette price and state and local tobacco control policies are added to the survey data. The cigarette price measure reflects the average state-level price for a pack of 20 cigarettes and is taken from the Tobacco Institute's annual The tax burden on tobacco. ${ }^{4}$ It is a weighted average of the prices of single packs, cartons, and vending machine sales and includes state-level excise taxes and the price of generics. To capture potential cross-border shopping for cigarettes that, if excluded, may bias estimates of price towards zero, an additional variable representing the largest price difference between the person's state of residence and states within 25 miles of the person's county of residence is also included. This variable is set equal to zero for those young people who live in states with lower prices than nearby states and for young people who live in counties more than 25 miles from another state.

Four variables capturing state and local tobacco policies are also merged into the data. The first is a dummy variable set equal to one in those states that earmark a portion of cigarette tax revenues for anti-tobacco activities and zero otherwise. Those states that set aside these funds are generally believed to be more aggressive in discouraging smoking.

The second is another dummy variable set equal to one in those states that have some form of smoker protection legislation and equal to zero otherwise. These laws typically protect smokers from discrimination in the workplace and elsewhere and may reflect a greater "pro-smoking" sentiment in the states that have them.

The final two variables are indices of clean indoor air restrictions and youth access laws passed at the state and local level. The index of clean indoor air restrictions represents the sum of five independent variables capturing the fraction of the population in the person's county of residence subject to state or local restrictions on smoking in private work sites, restaurants, retail stores, schools, and other public places.

The index of youth access is constructed similarly by summing five different variables capturing different aspects of youth access. The first two variables included in this index are dummy variables set equal to one if the state has a minimum legal purchase age of at least 18 and if the state requires point-of-sale signage stating the minimum legal purchase age. Two other variables included in this index represent the fraction of the county population in the person's county of residence that is sub- 
Table 1 Descriptive statistics by sex and race, Monitoring the Future surveys 1992-1994

\begin{tabular}{lllll}
\hline & Males & Females & Whites & Blacks \\
\hline & 53209 & 57508 & 74745 & 12897 \\
Currently smoking & $0.231(0.422)$ & $0.227(0.419)$ & $0.256(0.436)$ & $0.080(0.271)$ \\
Average real price of cigarettes $\dagger$ & $124.72(13.730)$ & $124.79(13.408)$ & $123.84(13.529)$ & $122.92(13.422)$ \\
State earmarks tax revenue & $0.157(0.364)$ & $0.160(0.367)$ & $0.129(0.335)$ & $0.104(0.306)$ \\
State smoker protection laws & $0.485(0.500)$ & $0.467(0.499)$ & $0.512(0.500)$ & $0.398(0.490)$ \\
Index of clean indoor air laws & $3.751(1.451)$ & $3.757(1.434)$ & $3.721(1.453)$ & $3.324(1.660)$ \\
Index of youth access & $3.985(0.979)$ & $3.960(0.981)$ & $3.949(0.987)$ & $3.955(0.990)$ \\
\hline
\end{tabular}

^Fraction of the youth that smoke; †cents per pack of 20 cigarettes (1982-84\$)

ject to restrictions on vending machine sales and distribution of free samples. The last variable included in this index represents the fraction of the county population who are living in areas where vendors are required to have a licence to sell tobacco products.

The data on state-level policies were taken from the Coalition on Smoking OR Health's $(\mathrm{CSH})$ annual State legislated actions on tobacco issues. ${ }^{5}$ Similar information on county and citylevel restrictions was obtained from the National Cancer Institute's monograph summarising major local control policies, updated with information from CSH. ${ }^{6}$

Descriptive statistics for the variables of interest by sex and race are provided in table 1 . As has been found in other surveys, smoking rates among young blacks $(8.0 \%)$ are significantly lower than those of young whites $(25.6 \%)$ in our sample. There is no significant difference in smoking prevalence by sex, however. Approximately $23 \%$ of young men and young women report currently smoking. Only a few of the policy variables differ across the groups. On average, fewer young blacks are found in states that pass smoker protection laws. Similarly, fewer black youths live in states with tougher restrictions on smoking in public places.

\section{Results}

Using as controls the variables described above, the probability of smoking in the previous 30 days was estimated for young men, young women, young blacks, young whites, young black men, young white men, young black women, and young white women using separate probit maximum likelihood specifications. Each specification includes a measure of the price of cigarettes along with the border-purchase variable. However, as the tobacco control policies are highly correlated, only one policy variable could be included in the regression equation at a time. We therefore estimated each of the eight sex/race specific specifications five separate times, once with just the price included and four times with price and a different tobacco control policy. As most of the policy variables are measured at the state level, standard errors are corrected for correlation created by having multiple observations within a single state using the cluster option in STATA 5.0. Although similar models were run using daily smoking instead of 30-day prevalence, these results are not presented. Models of daily smoking could only be estimated for some of the subpopulations due to a small number of observations (for example, only 387 young blacks in the sample are daily smokers). The results for daily smoking in those subpopulations we were able to estimate are consistent with the findings presented here for 30-day prevalence. The only notable difference is that the effects of price are larger for daily smoking than for past-month smoking.

Table 2 reports the marginal effects obtained from each of these separate regressions for the key policy variables, and table 3 summarises the main findings. In table 3, a dash indicates that the marginal effect of the variable on the probability of smoking was negative while the plus sign indicates that the marginal effect of the variable was positive. The average price elasticity resulting from the five different policy specifications of the models is reported in the final column. Although earmarking of state cigarette tax revenue to promote anti-tobacco activities has a negative and significant effect on smoking prevalence for young men and women, it is only smoking by young whites that is affected by this policy. State earmarking has no significant effect in any of the model specifications run separately for black youths. Smoker protection laws, on the other hand, have the largest positive effect on smoking rates by young blacks, and in particular young black males. Smoking prevalence of young whites, male and female, is not affected by the existence of smoker protection laws. Clean indoor air laws significantly decrease smoking prevalence among young white males, but have no significant effect on any of the other groups of adolescents. Stricter youth access laws, on the other hand, significantly decrease smoking rates among young black males and females but have no significant effect on the smoking prevalence of young whites.

Economists use the price elasticity of demand as a way of measuring the responsiveness of the demand for a commodity to changes in the price of that commodity. It is measured as the per cent change in the quantity of the product demanded, or in this case the percent change in the probability of smoking cigarettes, given a $1 \%$ increase in the commodity's price, or $\eta_{d}=\% \Delta \mathrm{Q} / \% \Delta \mathrm{P}$. When a change in the probability of using a product is examined instead of the actual quantity demanded, we refer to this as a prevalence elasticity. A value greater than one in absolute value indicates that the change in the probability of smoking is greater in percentage terms than the change in the price of the commodity, and we say that consumption is very responsive to changes in price. A value less than one in absolute terms would indicate that the change in the probability of smoking was smaller in 
Table 2 Predicted change in the probability of smoking

\begin{tabular}{|c|c|c|c|c|}
\hline & \multicolumn{4}{|c|}{ Single policy models—sex differences } \\
\hline & \multicolumn{2}{|l|}{$\operatorname{Men}(p=00.2312)$} & \multicolumn{2}{|l|}{ Women $(p=00.2267)$} \\
\hline & Policy & Price & Policy & Price \\
\hline \multirow{9}{*}{$\begin{array}{l}\text { Price of cigarettes } \\
\text { Earmarking of taxes } \\
\text { Smoker protection laws } \\
\text { Clean indoor air index } \\
\text { Youth access index } \\
\text { Average price elasticity }\end{array}$} & & $-0.0019(-50.43)$ & & $-0.0012(-20.50)$ \\
\hline & $-0.0206(-20.50)$ & $-0.0017(-50.94)$ & $-0.0356(-20.45)$ & $-0.0008(-20.56)$ \\
\hline & $-0.0037(-00.40)$ & $-0.0019(-50.68)$ & $0.0016(00.16)$ & $-0.0011(-20.49)$ \\
\hline & $-0.0078(-30.37)$ & $-0.0013(-30.40)$ & $-0.0014(-00.52)$ & $-0.0011(-20.14)$ \\
\hline & $-0.0030(-00.65)$ & $-0.0018(-40.93)$ & $0.000034(00.01)$ & $-0.0012(-20.70)$ \\
\hline & & 0.928 & & 0.595 \\
\hline & \multicolumn{4}{|c|}{ Single policy models - race differences } \\
\hline & \multicolumn{2}{|l|}{ Black $(p=0.0799)$} & \multicolumn{2}{|l|}{ White $(p=0.2557)$} \\
\hline & Policy & Price & Policy & Price \\
\hline \multirow{9}{*}{$\begin{array}{l}\text { Price of cigarettes } \\
\text { Earmarking of taxes } \\
\text { Smoker protection laws } \\
\text { Clean indoor air index } \\
\text { Youth access index } \\
\text { Average price elasticity }\end{array}$} & & $-0.0008(-10.77)$ & & $-0.0014(-40.37)$ \\
\hline & $0.0047(00.32)$ & $-0.0008(-10.61)$ & $-0.0259(-20.02)$ & $-0.0012(-40.78)$ \\
\hline & $0.0146(10.80)$ & $-0.0007(-20.01)$ & $-0.0091(-10.03)$ & $-0.0015(-40.27)$ \\
\hline & $-0.0013(-00.39)$ & $-0.0007(-10.45)$ & $-0.0043(-10.79)$ & $-0.0011(-30.02)$ \\
\hline & $-0.0066(-10.70)$ & $-0.0006(-10.57)$ & $0.0014(00.33)$ & $-0.0014(-40.20)$ \\
\hline & & 10.108 & & 0.639 \\
\hline & \multicolumn{4}{|c|}{ Single policy models—men only } \\
\hline & \multicolumn{2}{|l|}{ Black $(p=0.0911)$} & \multicolumn{2}{|l|}{ White $(p=0.2530)$} \\
\hline & Policy & Price & Policy & Price \\
\hline \multirow{9}{*}{$\begin{array}{l}\text { Price of cigarettes } \\
\text { Earmarking of taxes } \\
\text { Smoker protection laws } \\
\text { Clean indoor air index } \\
\text { Youth access index } \\
\text { Average price elasticity }\end{array}$} & & $-0.0013(-20.82)$ & & $-0.0019(-50.45)$ \\
\hline & $0.0146(00.86)$ & $-0.0014(-20.56)$ & $-0.0199(-10.57)$ & $-0.0017(-50.52)$ \\
\hline & $0.0194(10.95)$ & $-0.0011(-30.28)$ & $-0.0098(-00.98)$ & $-0.0020(-50.53)$ \\
\hline & $-0.0010(-00.28)$ & $-0.0012(-20.05)$ & $-0.0087(-20.94)$ & $-0.0013(-30.09)$ \\
\hline & $-0.0075(-10.39)$ & $-0.0011(-20.54)$ & $0.0012(00.24)$ & $-0.0019(-40.78)$ \\
\hline & & 10.646 & & 0.861 \\
\hline & \multicolumn{4}{|c|}{ Single policy models—women only } \\
\hline & \multicolumn{2}{|l|}{ Black $(p=0.0706)$} & \multicolumn{2}{|l|}{ White $(p=0.2584)$} \\
\hline & Policy & Price & Policy & Price \\
\hline Price of cigarettes & & $-0.0003(-00.70)$ & & $-0.0010(-20.41)$ \\
\hline Earmarking of taxes & $-0.0024(-00.17)$ & $-0.0003(-20.56)$ & $-0.0317(-20.03)$ & $-0.0007(-20.25)$ \\
\hline Smoker protection laws & $0.0104(10.21)$ & $-0.0003(-00.64)$ & $-0.0081(-00.81)$ & $-0.0010(-20.33)$ \\
\hline Clean indoor air index & $-0.0015(-00.39)$ & $-0.0002(-00.52)$ & $0.0001(00.04)$ & $-0.0010(-20.12)$ \\
\hline Youth access index & $-0.0054(-10.48)$ & $-0.0002(-00.50)$ & $-0.0001(-00.35)$ & $-0.0010(-20.41)$ \\
\hline Average price elasticity & & 0.4528 & & 0.4507 \\
\hline
\end{tabular}

z-Scores are in parentheses. Each row represents a different specification which, in addition to price and the tobacco-related policy noted in the row, includes an intercept, indicators of race, age, religiosity, rural residence, family structure, parental education, maternal work status, grade, year, average hours worked, and real income. Standard errors were adjusted for clustering at the state level.

percentage terms than the change in price, meaning that consumption is relatively less responsive to price.

Looking at the average price elasticities reported in the final column of table 2 we see that smoking prevalence among young men is much more sensitive to changes in price than smoking prevalence by young women, regardless of race. Smoking by young black men is the most price sensitive; a $10 \%$ increase

Table 3 Summary of findings by race and sex

\begin{tabular}{|c|c|c|c|c|c|}
\hline $\begin{array}{l}\text { Demographic } \\
\text { group }\end{array}$ & $\begin{array}{l}\text { Earmarking of } \\
\text { tax revenue }\end{array}$ & $\begin{array}{l}\text { Smoker } \\
\text { protection laws }\end{array}$ & $\begin{array}{l}\text { Clean indoor } \\
\text { air laws }\end{array}$ & $\begin{array}{l}\text { Youth } \\
\text { access laws }\end{array}$ & $\begin{array}{l}\text { Average price } \\
\text { elasticity } \\
\text { (across all models) }\end{array}$ \\
\hline Men & $-\star \star$ & - & $-\star \star \star \star$ & - & $-0.928^{\star \star \star}$ \\
\hline White & $-{ }^{a}$ & - & $-\star \star \star \star$ & + & $-0.861^{\star \star \star \star}$ \\
\hline Black & + & $+\star \star$ & - & $--^{a}$ & $-1.646^{\star \star \star}$ \\
\hline Women & $-\star \star$ & + & - & + & $-0.595^{\star \star}$ \\
\hline White & $-\star \star$ & - & + & - & $-0.451^{\star \star}$ \\
\hline Black & - & + & - & $--^{a}$ & -0.453 \\
\hline Whites & $-\star \star$ & - & $-^{\star}$ & + & $-0.639^{\star \star \star}$ \\
\hline Men & $-{ }^{a}$ & - & $-\star \star \star \star$ & + & $-0.861^{\star \star \star}$ \\
\hline Women & $-\star \star$ & - & + & - & $-0.451^{\star \star}$ \\
\hline Blacks & + & $+^{\star}$ & - & $-\star$ & $-1.108^{\star}$ \\
\hline Men & + & $+\star \star \star$ & - & $--^{a}$ & $-1.646^{\star \star \star}$ \\
\hline Women & - & + & - & $--^{a}$ & -0.453 \\
\hline
\end{tabular}

All probit regressions included controls for age, average weekly income, current grade, marital status, parental education, family structure, mother's work status while the child was growing up, existence of siblings, average number of hours worked weekly, living in rural area, and frequency of participation in religious services in addition to race and sex when appropriate. ${ }_{\star} \star \star$ Significance at the $1 \%$ level (two-tailed test); ${ }^{\star \star} 5 \%$ level (two-tailed test); ${ }^{\star} 10 \%$ level (two-tailed test); ${ }^{a} 10 \%$ level (one-tailed test). in the price of cigarettes is estimated to result in a $16.5 \%$ decrease in smoking prevalence among young black men, holding everything else constant. The same price increase would result in a reduction in smoking prevalence of $8.6 \%$ among young white men. Smoking prevalence among women is less responsive to price than it is among young men. While statistically significant effects of price are found for young white women, in most of the models, the price of cigarettes had no significant effect on the probability of smoking for young black females.

\section{Discussion}

It should be kept in mind when interpreting these findings that most of the tobacco control policies included in this analysis only measure the existence of a policy and not its actual enforcement. There is considerable evidence in the recent literature suggesting that it is the enforcement of these policies and not the policies themselves that change behaviour. ${ }^{38}$ This suggests that one interpretation of the findings presented here is that particular tobacco control policies are enforced differentially in a manner that is somehow correlated with sex and race. Such an interpretation cannot be ruled out without detailed information on the 
Table 4 Change in consumption associated with price increases from 1981-1990

\begin{tabular}{lcl}
\hline Demographic group & $\begin{array}{l}\text { Actual change in } \\
\text { smoking rates (\%) }\end{array}$ & $\begin{array}{l}\text { Predicted change in } \\
\text { smoking rates (\%) }\end{array}$ \\
\hline Decline by males & 9.8 & -58.4 \\
Decline by females & -7.6 & -37.4 \\
Decline by whites & 5.9 & -40.2 \\
Decline by blacks & -48.5 & -69.7 \\
\hline
\end{tabular}

enforcement activities surrounding each of the policies. However, the most consistently significant policy variable is the price of cigarettes, which is not a function of enforcement. Higher prices have a negative and significant effect on smoking prevalence for all of the groups examined, except for young black women, but even here there is significant variation in the responsiveness by subpopulation. It is possible that some of this variation may be due to correlation with unobserved factors that have not been adequately controlled for in our models, such as socioeconomic status. The models do include controls for parental education, mother's working status, and the individual's weekly income, but no clean measure of family income or wealth is available from the data. However, findings from another nationally representative study of young adults (ages 18-25) show similar differences in price responsiveness by sex and ethnicity, and this study does include more comprehensive measures of income. ${ }^{9}$

To what extent do the observed differences in price sensitivity explain the divergence in smoking trends that were observed in the 1980s? Assuming that young people's smoking prevalence elasticities are fairly constant over time, it is possible to use the elasticities reported in table 3 to predict the change in smoking prevalence expected given the $63 \%$ increase in real price that occurred from 1981 to 1990 . In table 4, we record the actual and predicted change in smoking prevalence for the four basic subgroups represented in the figure. It is clear from the differences in predicted and actual values that the change in price alone does not adequately explain the actual patterns of smoking prevalence for all of the subgroups. Given the elasticities calculated in table 3 and the enormous change in price during the 1980s, we would have expected to see smoking rates among all four groups decline, with smoking among black youths falling the most and smoking rates among young women falling the least. Although smoking rates among young blacks did experience the largest decline during the 1980 s, the decline was not nearly as large as our model predicts. The same is true for young women. Smoking rates among young men and young whites actually rose during the period, however, contrary to what our model predicts.
The poor performance of our model at explaining the shifts in smoking prevalence in these population subgroups during the 1980s is not that surprising as it assumes that everything else that may influence young people's smoking is held constant throughout the period. This was certainly not the case. For example, at the same time that the tobacco industry started raising the price of cigarettes, it dramatically increased its spending on advertising and promotion. Between 1981 and 1990 total advertising and promotional expenditures for the industry nearly tripled. ${ }^{1}$ This increase in advertising and promotion is not accounted for in our analysis and may be offsetting the effect of price on smoking rates. To the extent that advertising and promotional activities target specific subgroups more than others, and to the extent that some young populations may be more responsive to these activities, this increase in tobacco industry marketing expenditures is likely to influence young people's smoking rates differently as well. There may be other missing determinants as well.

Even with these shortcomings, it is clear from this analysis that different youths respond differently to changes in price and public policies. Significant differences exist by sex and race, suggesting that public health professionals and policymakers need to keep in mind who their target user is when determining policy. There is clearly not a "one size fits all" strategy for discouraging young people's smoking.

This research was supported by a grant from the US Centers for Disease Control and Prevention and the Robert Wood Johnson Foundation. An earlier version of this paper was presented at the March 1998 annual meeting of the Society for Research on Nicotine and Tobacco in New Orleans.

1 US Department of Health and Human Services. Preventing tobacco use among young people. A report of the Surgeon Gen-
eral, 1994. Atlanta, Georgia: Public Health Service, Centeral, 1994. Atlanta, Georgia: Public Health Service, Centers for Disease Control and Prevention, Office on Smoking and Health, 1994. (US Government

2 Tobacco Institute. The tax burden on tobacco. Washington, DC: Tobacco Institute, 1997.

3 Chaloupka FJ, Grossman M. Price, tobacco control policies, and youth smoking. National Bureau of Economic Research working paper 5740. NBER, 1996.

4 Tobacco Institute. The tax burden on tobacco. Washington, DC: Tobacco Institute, 1995.

5 Coalition on Smoking OR Health. State legislated actions on tobacco issues. Washington, DC: Coalition on Smoking OR Health, various years.

6 National Cancer Institute, Major local tobacco control ordinances in the United States, monograph 3. Bethesda, Maryland: US Department of Health and Human Services, Public Health Service, National Institutes of Health, 1993 .

7 Jason LA, Ji PA, Anes MD, et al. Active enforcement of cigarette control laws in the prevention of cigarette sales to minors. FAMA 1991;266:3159-61.

8 Wasserman J, Manning WG, Newhouse JP, et al. The effects of excise taxes and regulations on cigarette smoking. $\mathcal{F}$ Health Econ 1991;10:43-64.

9 US Centers of Disease Control and Prevention. Response to increases in cigarette prices by race/ethnicity, income, and age groups-United States, 1976-1993. MMWR 1998; 47:605-9. 